\title{
The Use Of Economic Impact Studies As A Service Learning Tool In Undergraduate Business Programs
}

John M. Misner, (Email: john.misner@sru.edu), Slippery Rock University

\begin{abstract}
This paper examines the use of community based economic impact studies as service learning tools for undergraduate business programs. Economic impact studies are used to measure the economic benefits of a variety of activities such as community redevelopment, tourism, and expansions of existing facilities for both private and public producers. Economic impact studies when structured as service learning projects provide an experiential learning environment for business students, affording them with the opportunity of applying the knowledge and skills learned in the classroom while at the same time engaging in community service. Such projects can expose students to the importance of corporate social responsibility and help involved faculty to remain current in their fields of expertise while providing pedagogical and practice oriented avenues for research. Clients gain access to expertise in a cost effective manner. When done effectively, service learning projects in undergraduate business programs generate goodwill and favorable publicity while helping academic institutions meet mission statements and address specific accreditation standards.
\end{abstract}

\section{Introduction}

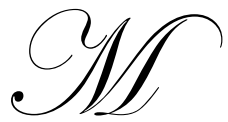

ore and more colleges and universities are pursuing the inclusion of service learning into their curriculums. Their reasons are many and varied. For many, service learning is looked at as an alternative form of experiential learning, integrating course material and volunteer service to communities. For others, service learning is a mechanism that allows these institutions to reach out into the local communities.

So, what is service learning? The American Association for Higher Education (AAHE) defines service learning in this way:

Service learning means a method under which students learn and develop through thoughtfully organized service that: is conducted in and meets the needs of a community and is coordinated with an institution of higher education, and with the community; helps foster civic responsibility; is integrated into and enhances the academic curriculum of the students enrolled; and includes structured time for students to reflect on the service experience. (1999)

Historically, service learning has been conducted in programs housed in the social sciences and humanities areas across campus. Recently, business programs have become more active in this area. Regardless of motive, effective service learning benefits all stakeholder groups. Students engaged in service learning projects find a connection of theory to practice that can help with career preparation. They also develop an awareness of community issues and problems. Faculty involved in service learning projects are frequently provided the opportunity to apply theory and knowledge to local problems. Agencies and small businesses within the community have access to "low-cost" expertise. University administrators are beginning to recognize that service learning can help in enhancing the image and reputation of the school. Perhaps more importantly, effective service learning in business programs helps to integrate university goals with state system mandates (for public institutions) while meeting specific accreditation standards. 
This paper will explore many of the issues and dynamics faced by business programs as they look towards the inclusion of service learning into their programs. Specifically, economic impact studies will be used as an example of a suitable tool for business programs. Separate sections will provide a brief literature search, discuss program adaptation and integration issues, discuss the use of economic impact studies as a service learning apparatus, explore relevant assessment issues, and provide concluding observations and remarks relating to further research.

\section{Literature Review}

Most of the theoretical research related to service learning to date has focused on the concept of experiential learning. Kolb (1984) postulated in his experiential learning model that people learn by and through concrete experiences, reflective observations, abstract conceptualization, and active experimentation. Since service learning should involve the integration of course material with volunteer service and some form of personal reflection on reporting of the outcomes, service learning as applied to Kolb's model emphasizes the combined processes of concrete experiences and reflective observations.

Godfrey (2000) hypothesizes that service learning enhances the technical skills of students by combining the concrete experiential base outlined by Kolb. Furthermore, Godfrey posits that the most powerful learning occurs through the humanization of problems. Such humanization is a common occurrence in service-learning projects. Waddock and Post (2000) extend Godfrey's positions and address the following characteristics of successful service learning projects and programs:

- $\quad$ Service learning engages the whole person.

- $\quad$ Service deepens the entire learning process.

- $\quad$ Service provides an unparalleled opportunity for reflection.

- $\quad$ Service links theory to practice.

- $\quad$ Service provides a socially useful contribution to the community in the short term.

- Service assists the community in the long run.

Heffernan (2001) introduces six models for service learning. "Pure" service learning courses send students out into the community to serve. In disciplined-based service learning, students use course content as a basis for their analysis and understanding. With problem based service learning, students act as consultants working with community clients identifying particular needs, and recommending specific solutions. Capstone courses can provide an attractive venue for service learning. Capstone courses are generally offered in the student's final year of study and offer the opportunity to transition from the classroom into the work world. Service internships can be structured to allow a student to work periodically with a community client. Finally, community based research is an option for the rare student highly experienced in community work.

Regardless of the model chosen, it is paramount to maintain an academic learning environment. In this light, Howard (2001) identified ten principles of good practice for service learning pedagogy. They are as follows:

- $\quad$ Academic credit is for learning, not for service.

- Do not compromise academic rigor.

- $\quad$ Establish learning objectives.

- $\quad$ Establish criteria for the selection of service placements.

- $\quad$ Provide educationally-sound learning strategies to harvest community learning and realize course learning objectives.

- $\quad$ Prepare students for learning from the community.

- $\quad$ Minimize the distinction between the students' community learning role and classroom learning role.

- $\quad$ Rethink the faculty instructional role.

- $\quad$ Be prepared for variation in, and some loss of control with, student learning outcomes.

- $\quad$ Maximize the community responsibility orientation of the course. 
In the College of Business at Montana State University-Bozeman, students are exposed to service learning in both the Freshman and Senior Seminars. Lamb, Lee, Swinth, and Vinton (2000) summarized the benefits they have witnessed in their programs. They are as follows:

- $\quad$ Enhanced relationship and collaboration with the community.

- $\quad$ Broader definition of self as a stakeholder in the community as well as of the community as a stakeholder in the College of Business.

- $\quad$ Enhanced appreciation of non-profit businesses and organizations.

- Systematic learning experiences that challenge students to think critically, apply their learning in the context of service, and analyze firms' organizational culture and service commitment.

Misner (2003) reaffirmed the many benefits highlighted by Lamb, Lee, Swinth, and Vinton, and concluded from his own experiences that by engaging in service learning:

- Students develop a keen awareness of "corporate social responsibility" while learning to work together in the identification of problems and creation of solutions.

- $\quad$ Faculty will find it necessary to hone their own skills while developing stronger mentoring relationships with their students.

- University administrators will discover that the image and reputation of the school is enhanced both in the local communities and with accreditation agencies.

- $\quad$ Communities benefit when smaller businesses and non-profit agencies have access to faculty expertise and enthusiastic hard-working students.

\section{Adaptation, Integration, and Benefits of Service Learning}

The inclusion of service learning into business programs serves many useful purposes. For public institutions, service learning provides a means for the university to meet certain state mandates. It is common practice for state systems of higher education to create performance indicators for their member institutions. Frequently, budget allocations back to member schools are impacted by these performance measures. Business discipline related service learning activities can help institutions meet such performance criteria.

Service learning helps academic institutions meet goals established in vision and mission statements. These statements typically focus in part on the intellectual and social development of students while meeting certain needs of the local community and broader regions.

Business programs face accreditation standards and guidelines. The Association to Advance Collegiate Schools of Business (AACSB) states in the preamble to Eligibility Procedures and Standards for Business Accreditation (as adopted April 25, 2003, and revised January 1, 2004), that, "management education must prepare students to contribute to their organizations and the larger society and to grow personally and professionally throughout their careers." AACSB organizes their required standards into three categories; strategic management standards, participants standards, and assurance of learning standards. Service learning can be directly applied to help meet certain standards within these categories.

Specifically, AACSB mandates that its accredited members:

- Innovate in instructional processes.

- $\quad$ Actively involve students in the learning process.

- $\quad$ Encourage collaboration and cooperation among participants. 
Undergraduate degree programs are charged to include learning experiences in such general knowledge and skill areas as:

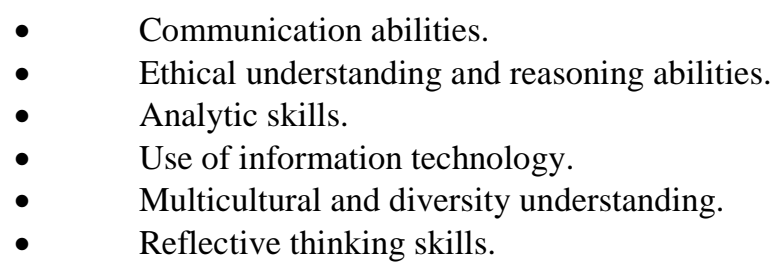

Service learning projects in business programs can and should directly address each and every bulleted item. By integrating these skills and attributes into a service learning project, students acquire first hand knowledge of what it takes to organize work, make sound business decisions, communicate these decisions, and react to unanticipated events.

The standards underscore the importance of the active engagement of students in the learning process. Individual students are charged to:

- $\quad$ Operate with integrity in their dealings with faculty and other students.

- $\quad$ Engage the learning materials with appropriate attention and dedication.

- $\quad$ Maintain their engagement when challenged by difficult learning activities.

- $\quad$ Contribute to the learning of others.

- $\quad$ Perform to standards set by the faculty.

Service learning projects should provide for student involvement in the identification of business problems and the crafting of solutions to such problems, while working within a team environment. The necessary studentfaculty interactions in such projects will also provide the opportunities for mentored reflections on the work and actions of the students.

It is imperative that faculty remain current in their fields of expertise, while finding alternative ways of transferring that knowledge to their students. To quote from the AACSB Eligibility Procedures and Standards for Business Accreditation: "When faculty members are current with the applicability and relevance of ideas and concepts in their field, instruction, practice, and inquiry benefit. The critical factor in determining whether faculty members bring current and relevant information is the impact of faculty members development activities on the mission of the school. (page 45)" Faculty engaged in service learning open themselves up to the opportunity of engaging in two different types of professional development. They can engage in learning and pedagogical research simply by writing and reflecting upon their service-learning experiences. Also, their service learning actions can provide for contributions to practice, leading to articles in practice-oriented journals and the creation and execution of executive courses.

\section{Economic Impact Studies}

Conceptually, economic impact studies are not difficult to conduct. First, the amount of dollars injected into the local community by the client agency is determined. Then the appropriate local spending multipliers are applied to these amounts to estimate the total impact on the local economy. In fact, local multiplier effects are very straightforward. Cash flows paid out as employee compensation or for goods and services is spent and re-spent, resulting in a final increase that is some multiple of the initial change. At each "round" of spending, some fraction is withdrawn from the spending flow in the form of household savings and taxes paid. Any imports are also leakages from each round of spending. Imports consist of final goods and services as well as the intermediate inputs that are purchased outside of the area. Total imports are subtracted from total expenditures within the region for final demand calculation. 
The "openness" of an economy depends upon the degree to which it is subject to income leakages due to payments to economic agents outside the region. Generally, the smaller and less diversified the region, the more open the economy. The size of the multiplier effect will also then vary with the degree of openness of the region. Large metropolitan areas are more likely to produce a wider array of final demand goods for the local market and will also utilize relatively more intermediate inputs. Small communities are more likely to emphasize retailing of commodities produced elsewhere. The smaller the region in question, the greater the leakages, and therefore the smaller the multiplier effect.

A systematic analysis of the total economic impacts of programs and projects in the affected regions must account for the inter-industry relationships within the regions as these relationships largely determine how regional economies are likely to respond. Thus, regional input-output (I-O) multipliers, which account for inter-industry relationships within regions, are useful tools for regional economic impact analysis. The calculation of input-output multipliers first requires the creation of an I-O table that shows the distribution of inputs purchased and sold for each industry in the region. Businesses in a region are surveyed in order to determine which goods and services are purchased by industries in the region and whether these goods and services are purchased from other industries in the region or from industries in other regions. In this way it can be estimated how much demand will be increased in the region by the second round of spending when initial purchases occur from an industry in the region.

The user must determine which industries the program or project under consideration initially affects. The specification of these industries in the maximum possible detail will promote the accuracy of the impact analysis. Detailed data on the purchases of goods and services (including labor) made by the initially affected industry is called "bill-of-goods" data. When demand in the initial industry changes, the impact on the demand for each good and service in that producer's bill-of-goods can be estimated. The multipliers calculated this way are called final demand multipliers. The final demand multipliers can be applied to the change in demand in that industry to calculate the economic impact on output, earnings and employment in that industry. These effects can then be summed across all the affected industries to calculate the total economic impact on output, earnings and employment for the region.

Procedurally, economic impact studies are not difficult to conduct, provided complete and detailed data are available. In practice however, determining the appropriate local multiplier becomes a more complex issue. Traditionally, multipliers have been calculated or borrowed from other studies. Calculating multipliers is a complex process requiring complete and detailed input/output information by industry that frequently is not available or is costly and time consuming to obtain. Borrowing multipliers from other studies draws into question the accuracy of the application. These concerns can be alleviated through the purchase and use of RIMS II multipliers.

The Bureau of Economic Analysis (BEA) of the U.S. Department of Commerce has developed a method for estimating regional I-O multipliers known as RIMS II (Regional Input-Output Modeling System). RIMS II creates an I-O table that shows the distribution of the inputs purchased and the outputs sold for each industry. RIMS II derives the I-O table from two data sources: BEA's national I-O table, which shows the input and output structure of nearly 500 U.S. industries; and BEA's regional economic accounts, which are used to adjust the national I-O table in order to reflect a region's industrial structure and trading patterns. RIMS II multipliers can be estimated for any region composed of one or more counties and for any industry or group of industries in the national I-O table. The cost of estimating regional multipliers is relatively low because of the accessibility of the main data sources. According to empirical tests, the estimates based on RIMS II are similar in magnitude to the estimates based on relatively expensive surveys. ${ }^{1}$

\footnotetext{
${ }^{1}$ Brucker, S.M., S.E. Hastings, and W.R. Latham III, “The Variation of Estimated Impacts from Five Regional Input-Output Models," International Regional Science Review 13 (1990): 119-139.
} 


\section{Economic Impact Study Experiences}

In this section, two specific experiences are discussed: the initial experiment and a classroom adaptation. Each study was funded in part with "mini-grants" provided through Slippery Rock University's Institute for Community, Service-Learning, and Non-Profit Leadership.

\section{The Initial Experiment}

In the fall of 2001, the author was approached by a private church affiliated social service agency in western Pennsylvania, which was attempting to raise funds for an expansion project. Specifically, the agency was interested in conveying the impact that they had on the economy of the local community. I indicated that what they were requesting was an economic impact study, and eagerly agreed to help them in a study.

My motives in agreeing to help were threefold. First of all, the study would provide an opportunity to "practice my craft." Secondly, I felt a need to help this agency. Finally, I viewed this opportunity as a pedagogical experiment to determine if I could develop a methodology for conducting economic impact studies and writing business plans that could be adapted as service learning projects in the classroom. Economic impact studies and business plans are of vital importance to nonprofit private agencies and smaller businesses. Both aid in fund raising and grant acquisition.

To assist with the study, I "recruited" the assistance of four excellent students (three finance majors and one economics major). Our first step was to tour the social service agency's facility. The agency provides a psychiatric residential treatment program for children with mental health issues and psychiatric diagnoses. Our student team was visibly moved as we toured the group homes, emergency shelter facilities and the special school operated by the agency. They were more than ready to "go to work." The next step was to collect and compile the necessary financial data to apply to RIMS II multipliers purchased from the BEA. As part of our working agreement, the agency provided us with detailed financial data. The team of students was used to sort and compile this data for use in the study. The final step was to present the study first to the director of the agency and then to it's board of directors.

As a starting point, the accumulative impacts of the agency's operations on the defined regions were measured up to the point of the start of their expansion project. To this end, detailed financial statement expense information was sorted into one of 38 industry aggregations as organized by the BEA. Then, depending on the specific region and the relative proportions of expenditures staying in the region, subtotals were calculated for each industry grouping. The multiplier effects were summed across the industries and added to the initial activity to determine the total economic impact on output, household earnings and employment in the selected regions.

After completion of the historical analysis, certain assumptions were made and projections generated based on the proposed expansion. The economic impacts from the projected expanded operations were measured using the historical template and methodologies.

The last step of the process was to present the findings to first the Executive Director of the agency and then to the agency's Board of Directors.

This particular experience gave strong indications that economic impact studies can certainly be a vehicle for service learning in capstone courses, especially in the disciplines of economics and/or finance. Private nonprofit agencies and smaller businesses offer a unique opportunity in that they have a demonstrated need for such studies and frequently lack the expertise to conduct them and/or the funds to purchase them. The students benefited by applying classroom knowledge to real life situations. My experiences with the client agency and team of students demonstrated that a whole world of opportunity was opened to our students. They saw first hand through the site visit, the work the client agency was doing with a special needs population. The thought that they could help really opened their eyes to their own social responsibility and how their talents and knowledge was useful. 


\section{Classroom Adaptation}

During the fall semester of 2003, I took service learning directly into the classroom. A substantial project for my Finance Seminar class involved the creation of an economic impact study for a nonprofit continuing care retirement community located 45 miles north of the University. The company is in the middle of a multi-million dollar expansion project, and was hopeful that an economic impact study would help them in the equity portion of their fund raising efforts.

There were 15 students in my Finance Seminar class. Each student was a senior. Twelve were finance majors, and the remaining three consisted of an economics major, a marketing major, and a management major. The project itself constituted $30 \%$ of their course grade.

During the summer, I met with the company's management on two occasions to discuss the parameters of the study and gather information consisting of copies of audits, financial projections, bond indentures, marketing studies, and company brochures. It was at this time that I also applied for and received a service learning minigrant, and placed an order with the U.S. Department of Commerce, Bureau of Economic Analysis for the necessary RIMS II final demand and direct effect economic multipliers.

The primary purpose of this study was to measure the historic and projected economic impact of the retirement community on its county of domicile. The historic impacts were measured for the years 2000, 2001, and 2002. Data through mid-August 2003 was annualized to estimate the impacts for 2003. Projected impacts were measured for the years 2004 through 2013.

On the first day of class, I outlined the project and its parameters and provided each student with a packet of materials consisting of company information, and descriptive material relating to the mechanics of economic impact studies. They were challenged to pour through the company specific material in preparation for our scheduled site visit ten days later. In the two subsequent class sessions prior to the site visit, we discussed in detail the company provided information and generated a list of questions for senior management.

At the site visit, we toured a representative sampling of all facilities (independent living cottages and apartments, assisted living, and Alzheimer's assisted living). We visited with one particular cottage resident who was an alumnus of the university. She made quite an impression on the class with her positive outlook and eager demeanor. When the class explained to her what we would be doing, she challenged them to do a "wonderful job" since she was attempting to convince senior management to build a swimming pool, and had been told that an additional $\$ 1,000,000$ would have to be raised for that purpose. Needless to say, the class adopted "Mrs. H." and her cause.

The site visit culminated with a working luncheon hosted by senior management. The students took approximately one hour to ask the questions that we had derived back in the classroom. The Executive Director complemented the group on the depth and thoroughness of their preparations.

Upon returning to campus, the class was divided into five teams. One team was assigned the task of gathering demographic information and conducting a market analysis. The other four teams were each assigned a previous year's $(2000,2001,2002,2003)$ financial statements. As a starting point, historic expenses (payroll and vendor disbursements) were sorted by zip codes to isolate region expenses. Vendor disbursements were categorized as "frequent" and "non-frequent" expenses. The frequent vendor disbursements were then slotted into either one of 490 U.S. detailed industries or 38 industry aggregations. Once slotted into the appropriate industries, the final demand multipliers for output, earnings, and employment were applied to determine the multiplier effects of each disbursement. These multiplier effects were summed across industries and then added to the initial level of disbursements to determine the total impacts on output, earnings and employment. Upon completion of the historical portion, similar treatment was given to the financial projections. 
In addition to the "Final-Demand" multipliers utilized as the basis of this study, RIMS II provides "DirectEffect" multipliers for earnings and employment. The direct-effect earnings multiplier measures the total dollar change in earnings of households employed by all row industries that results from a $\$ 1.00$ change in earnings paid directly to households employed by the industry corresponding to the entry. The direct-effect employment multiplier measures the total change in the number of jobs in all row industries that results from a change of one job in the industry corresponding to the entry. This information was also included in the study.

The study took about seven weeks to complete. Approximately one third of the class periods during this time were set aside to review the work that was being done by each group, answer their questions, and to issue new directions and deadlines going forward. I also met frequently outside of class hours with members of each group.

Upon completion of the study, senior management came to campus and the class presented its findings in an hour-long presentation. The client was impressed with the depth and thoroughness of the study. The Executive Director informed the class that the firm would be looking to hire a financial analyst in the near future and that he would be eager to discuss the position with any of them. He then asked for questions from the students and one asked the following; "Will you be able to raise the capital needed for the swimming pool for Mrs. H. and her friends?" His reply was; "This study will help me to do that!"

\section{Assessment Issues}

When service learning projects are conducted in the classroom, assessment for grading purposes becomes an issue. It is paramount that the final product is of high caliber, yet it is naïve to think that every participant will perform at the same level. This can be particularly true when the class is broken into smaller teams/groups. Group dynamics are such that occasionally not every member works as diligently as they should. It is also a common occurrence for frictions to develop among team members. Many professors who assign group work have the group members grade each other as to their effort and level of participation. I chose not to follow this approach in my Finance Seminar class.

In the class, I preached that everyone was responsible for the quality of the final product of our research. I instituted a policy that there are no excuses for missed deadlines or work of poor quality. Natural leaders floated to the top in each group, taking responsibility for time deadlines, and checking on the quality and accuracy of the work of other group members. Yet it became evident to me that not all of the students were "pulling their weight." Those that were actively engaged learned a valuable lesson that quality work needs to be done in a timely fashion. But, I also felt an obligation to flush out those who gave less than a full effort with the project. My tool for this was the final exam.

Forty percent of the final exam dealt with the study. I asked the following essay questions:

- $\quad$ Explain the concept of "final demand" multipliers.

- What are the key economic and demographic factors in the continued success of the firm?

- It is now five years later. You have been retained by the firm to re-visit the economic impact study. Prepare and comment on a list of information and materials that you will need to begin your analysis. What do you expect to find?

I am confident that these questions effectively flushed out those who were not actively involved in the project. The four students that I was suspicious of had great difficulty answering the questions, and were graded accordingly.

An equally important part of assessment is measuring the impact the experience had on the students. For evidence of this, I turned to our student course evaluation form that is called the "Student Survey of Course Effectiveness." Two statements on the survey were of particular interest: 
- $\quad$ The course provided opportunities for me to use critical thinking.

- $\quad$ The teaching in this course was effective.

One hundred percent of the student responses to these two statements were in the "strongly agree" category. The survey form also leaves space for written comments from students. One student wrote; "I really enjoyed working on the (client) project. I think it was a great opportunity for us students to be more involved in real-life, hands-on business activities."

\section{Summary and Conclusions}

Economic impact studies can certainly be an effective service learning experience in undergraduate business programs, particularly if conducted in higher level finance and/or economics courses. If structured properly, all participants and stakeholders benefit.

Students benefit by applying classroom knowledge to "real life" situations. They witness first hand how one prepares for client meetings. They develop a greater appreciation for time deadlines and the importance of pulling their own weight. Furthermore, the community service element introduces them to the importance of corporate social responsibility, and helps them make a connection with very diverse populations.

The client benefits in that they have access to expertise they do not possess and are provided with a service and product that can otherwise be quite expensive to purchase.

Faculty involved in service learning projects will find an opportunity to "practice their craft." This encourages currency in the discipline and opens the door to practice-oriented research as well as pedagogical research. Also, the nature of the service learning experience will lead to proactive mentoring of students.

Success in service learning is enhanced if the administration within the university strongly supports the concept and process. The university will benefit from service learning projects in a multitude of ways. From an accreditation perspective, service learning projects help to demonstrate an undergraduate business program's commitment to certain standards of excellence. Community involvement will enhance the institution's image and reputation. These factors should have a positive influence on student recruitment and fund raising.

Finally, it needs to be emphasized that service learning as applied to undergraduate business programs is in a relative stage of infancy. Therefore the research to date does not provide the depth or breadth to allow us to predict the most effective modes. Accordingly, it is paramount for faculty engaged in service learning, particularly those engaged in undergraduate business programs, to communicate with others their experiences, while creating assessment apparatus that will generate data for analysis.

\section{References}

1. American Association for Higher Education. (1999). Service-learning in the disciplines 18-volume monograph series.

2. Godfrey, P.C. (2000). “A Moral Argument for Service-Learning in Management Education.” In Working for the Common Good: Concepts and Models for Service-Learning in Management, edited by P.C. Godfrey and E.T. Grasso, pp. 21-41. Washington, D.C. American Association for Higher Education.

3. Heffernan, K. (2001). Fundamentals of Service-Learning Course Construction. RI: Campus Compact; 2-7, 9.

4. Howard, J. ed. (2001). Michigan Journal of Community Service Learning: Service-Learning Course Design Workbook. University of Michigan: OCSL Press. 16-19.

5. Kolb, D.A. (1984). Experiential Learning. Englewood Cliffs, NJ: Prentice-Hall.

6. Lamb, C.H., J.B. Lee, R.L. Swinth, K.L. Vinton. "Learning Well by Doing Good: Service-Learning in Management Education." In Working for the Common Good: Concepts and Models for Service-Learning 
in Management, edited by P.C. Godfrey and E.T. Grasso, pp. 167-178. Washington, D.C. American Association for Higher Education.

7. Misner, J.M. (2003). "Service Learning in Undergraduate Business Programs," Proceedings of the Pennsylvania Economic Association 2003 Annual Conference.

8. Waddock, S., J. Post. (2000). "Transforming Management Education: The Role of Service-Learning." In Working for the Common Good: Concepts and Models for Service-Learning in Management, edited by P.C. Godfrey and E.T. Grasso, pp. 43-54. Washington, D.C. American Association for Higher Education.

$\underline{\text { Notes }}$ 